\title{
AC 2008-2369: PROMOTING PROFESSIONAL DEVELOPMENT IN UNDERGRADUATE ENGINEERING USING LABORATORY TEAM PROJECTS: A CASE STUDY
}

\section{Gregory Davis, Kettering University}

Gregory W. Davis, Ph.D., P.E. is a Professor of Mechanical Engineering at Kettering University, formerly known as GMI Engineering \& Management Institute. Acting in this capacity, he teaches courses in the Automotive and Thermal Science disciplines. He also serves a Director of the Advanced Engine Research Laboratory, where he conducts research in alternative fuels and engines. Greg is active on the professional level of SAE, currently serving as a Director on the SAE Board of Directors (term, 2007-2010), a Director on the Publications Board, and Past-Chair of the Engineering Education Board. He is also active in numerous committees.

\section{Craig Hoff, Kettering University}

Craig J. Hoff, Ph.D., P.E. is a Professor of Mechanical Engineering at Kettering University. He teaches thermal science and automotive engineering. His research interests include fuel cell and hybrid electric vehicles. Dr. Hoff is also the faculty advisor to the Kettering Formula SAE racecar team. 


\section{Promoting Professional Development in Undergraduate Engineering Using Laboratory Team Projects: A Case Study}

Good professional communication skills and the ability to work in teams are critical skills demanded by engineering companies. Further, in order to maintain competitiveness and to work in the global marketplace, engineering companies are increasingly supporting the creation and use of professional standards that are developed by engineering societies. Unfortunately, many undergraduates have historically received little or no education regarding this aspect of engineering.

This paper describes the efforts to provide students with laboratory-based projects which provide students with significant exposure to professional engineering standards and practices. These projects require the students to read professional standards that pertain to the particular topic under study and to operate vehicles while using professional automotive engineering tools.

\section{Introduction}

Many undergraduates are largely unaware of the resources available at professional engineering societies. These resources range from professional codes and recommended practices to technical papers, and professional contacts. These resources can help young engineers to get a "jump start" on their peers.

Because of the need to cover many fundamental engineering topics in core courses, it is difficult to set aside sufficient time for hands-on, professional work. Often experimental work is concentrated into specific laboratory courses where students tend to be given detailed, step-bystep instructions on how to use the lab equipment and calculate the results. This approach is not the best way to prepare the students for the reality of professional engineering practice.

It can be difficult for faculty to devote time in providing exceptional design and applied experiences to undergraduates while also trying to develop their research. Often faculty members find that these priorities compete for their time. This is particularly difficult for young faculty. Further, young faculty members increasingly have extremely limited work experience in the engineering profession. This has led to a gap between what universities are teaching, and what engineers are expected to know in industry. ${ }^{1}$ Engineers in industry spend much time working on complex system integration, yet few engineering undergraduates understand this process. ${ }^{2}$ Bokulich [2] adds "the state of education in this country, especially in science, engineering and technology, has become a matter of increasing concern to many of us in American industry."

At the graduate level, industry and universities actively collaborate in research and development programs. This results in a supply of highly qualified technical specialists which industry uses to continue the process of development. This collaboration is not typical at the undergraduate level, and industry simply "accepts the 'output' from university with the knowledge that they have to complete the training process through in-house training programs." 3 In an increasing competitive global economy, this practice is not sustainable. 
In order to meet the needs of industry, Universities must place a renewed emphasis on teaching the practice of engineering. In order to teach the practice of engineering, students must be challenged to study the complex interactions of real engineering systems. Further, students must be exposed to professional standards and organizations, governmental regulations, team dynamics, and societal concerns. In short, students must be afforded the opportunity to practice engineering, learning how to apply the underlying scientific principles to the design of these systems.

In order to expose students to the benefits afforded by professional societies and to develop their hands-on abilities, projects are assigned which rely heavily on the use and knowledge of professional recommended practices and standards. These resources also help to lessen the burden imposed on faculty in developing these types of exercises. Faculty members no longer have to work independently to compose and develop the exercises; they can rely on the work of others in the profession. This is particularly helpful for young faculty or faculty with limited exposure to professional practice.

The particular course presented in this paper is an elective undergraduate/graduate level course in Automotive Powertrains. In this course both computational and experimental projects are integrated into the core material and are taught as part of more traditional lectures.

\section{Introduction to Automotive Powertrains Course}

As its name implies, this course introduces mechanical engineers to the design and selection of automotive powertrains. Topics covered include, the development and analysis of road loads on the vehicle, and the evaluation of the performance of various engine types used to propel the vehicles. Students then learn how these systems are combined using different types of transmissions and drive systems in order to create the vehicle powertrain. Finally, students learn how these sub-systems interact, and how the selection of drive ratios leads to differences in acceleration performance and fuel economy.

By developing simple mathematical models for each of the components, students develop a physical understanding of the components. By connecting the component models, students develop an understanding of the complex powertrain system. This approach is referred to as Model-Based Design and is a common technique used by industry to design large systems. ${ }^{4}$

Part of the course is devoted to traditional lecture time, but a large portion of the course is used to present the students with challenging computational and laboratory projects. During class time, students are provided with an overview of the project and the experimental equipment. In addition the students are provided with the user manual for the equipment and are expected to 'figure it out' from there, much like they would have to do in the 'real world.' As part of these exercises, students are required to research prevailing professional best practices and standards in order to complete the assignments. Further, students are required to work in teams and perform these projects on their own outside of the scheduled class time.

While the teams are not required to be multi-disciplinary, many teams recruit students from various backgrounds to help with the diverse requirements of these challenges. For example, some of the students are 'gear heads' and others are pure academics who don't know which end 
of a wrench to hold. Some are very organized and others work best at deadlines. Successful teams find ways to work with these differences.

The nature of this course requires students to instrument and test drive vehicles on open roads. Because of this, each team is given opportunities to setup and use the equipment during scheduled times outside of class hours. Typically, a week is dedicated for each laboratory exercise. In order to facilitate this process and to provide additional responsibility, each team must host one of the exercises. The requirements of a host team include:

- Assembling the equipment

- Testing equipment, including working with the professor to set up the test

- Taking data (a data set must be taken and analyzed at least one week before the lab date). This data must be submitted to the Professor along with the lab write-up corrections so copies can be made at the copy center.

- Distributing data to class/Scheduling time to help other groups conduct the laboratory

- Providing a "what-went-wrong, what-went-right" report due one week after the lab with continuous improvement ideas (and continuous improvement actions).

- Each group that hosts the lab must clean up immediately after the lab failure to do so will result in a $10 \%$ reduction in points.

Assigning host teams has the two-fold benefit of requiring the teams to coordinate and to work together, while freeing the faculty member from the time burden of monitoring all of the outside activity. Further, the faculty member can get early feedback on changes/improvements directly from the host team. This allows the faculty member to continue to develop and refine the exercise.

Requiring the teams to perform the laboratory exercise on their own time provides a better simulation of the requirements they will face in their careers. The teams will need to become self sufficient, learning to rely on the use of manuals, and professional standards, etc. in order to perform their jobs. In order to help them begin to achieve this process, faculty members provide a more detailed tutorial to the host team, and lists of references for all teams. Two hour time slots are setup to conduct each exercise. If a team fails to complete the exercise during this time slot, they must schedule another time with the host team. This encourages teams to come prepared to test.

An example laboratory exercise is presented in the Appendix. This exercise, a vehicle coast down laboratory, is assigned relatively early in the course. A close reading of the handout reveals that the teams could not successfully complete the assignment without consulting two SAE standards. These standards are listed by number in several places-including the reference section at the front of the handout. Because it is assigned early in the class, a series of pre-lab questions has been provided in order to provoke the teams into thinking about the requirements before coming to the laboratory. This type of "Hand-holding" is progressively decreased throughout the semester. Ideally, the students should only need to be provided with the front page of the assignment. Unfortunately, experience has taught us that undergraduate students generally require some additional help; therefore, most assignments still include a theory section and a list of questions to be answered. Later assignments do not generally include a list of prelab questions. 
The theory section is drawn from the references themselves. This helps relate the material in the references directly to that studied in the lecture. It also provides material for the faculty members to draw upon in preparing the exercise.

While reviewing the standards, the teams will find that these resources can actually help them to complete the exercise. For example, the J1263 standard even has a sample data sheet. If the students are really ambitious, it also includes sample computer code with which they could make a professional level calculation.

\section{Course Benefits}

It is hoped that these types of exercises expose the students to the benefits of looking at professional references. Many students at the undergraduate level have not yet realized that other professionals have faced many of the same problems and have developed practices and standard methods of solution. Because of our emphasis on the science underlying engineering in core courses, the students often feel that they are supposed to derive everything from first principles. In the practice of engineering, we often rely on the work of others in addressing the various concerns involved in the solution of a common problem. Objective data which quantifies the outcomes of this approach is difficult to obtain. It is interesting to note that the University subscription to the SAE digital database reveals that Kettering University students download over 1800 technical papers and standards each year. This in a University of under 2500 students.

Formal course evaluations reveal that the general response of students is very favorable to this course. Although students sometimes complain that the class is too much work, the class is usually over-loaded.

Further, many students return after graduation to express gratitude for how the course helped to prepare them for their careers. Many of these graduates have become actively involved in the engineering societies at a professional level, serving on committees and authoring publications and presentations.

In fact the positive support from these graduates (and the employers that have hired them) has resulted in the creation of a professional development short-course, which is taught by the course faculty members. A survey of these graduates will be attempted in the future to obtain more definite subjective evaluation of the course benefits.

\section{Conclusions}

This paper has briefly described some of the classroom activities conducted by the Kettering faculty and students which rely on the use of professional standards as a means of exposing students to some of the benefits of affiliation with professional societies. In this process, the authors have tried to help students make the transition from student to practicing engineer. Along the way, students are encouraged to become active members of professional societies, gaining, perhaps an early advantage over their peers while ultimately helping to contribute to the future of their profession. 
The students that participated in these activities believe that their education was enhanced by their participation. The alumni's responses also indicate that industry employers are benefiting because they are able to hire more experienced students.

Faculty, too, benefit from this collaboration. They can devote time to projects that enhance undergraduate educational opportunities, while minimizing the time commitment required. This is a rare "win-win."

It is hoped that this paper will help other faculty to find ways to introduce professional practices into the curriculum. Young faculty members, in particular, sometimes lack much professional experience and tend to teach to the textbook, only including the science of engineering. Using professional practices helps these faculty members to become familiar with the requirements and needs of industry while, at the same time, providing a more balanced experience for their undergraduates.

\section{Acknowledgements}

This work has been conducted with the help of many faculty, staff, students, and external supporters. The authors would particularly like to express their gratitude to the following individuals: Mr. Ray Rust, Mr. Joe Koch, and Mr. Clint Lee, Engineering Technicians for their contributions.

\section{References}

1. McMasters, and J.H., Matsch, L.A., "Desired Attributes of an Engineering Graduate-An Industry Perspective," Proceedings of $19^{\text {th }}$ AIAA Advanced Measurement and Ground Testing Technology Conference, American Institute of Aeronautics and Astronautics, Inc., AIAA-96-2241, 1996.

2. Bokulich, F., et al., "Wanted: Aerospace Engineers," Aerospace Engineering, SAE Publications, 21 (4), pp. 1824, 2001.

3. Fieldhouse, J.D, "The Education of Automotive Engineers to Meet the Global Demands of the $21^{\text {st }}$ Century," Society of Automotive Engineers, Paper 2008-01-1295, April 2008.

4. Herniter, M.E., et al., "Combining Passion with Fundamentals - Applying Model-Based Design to Education," Society of Automotive Engineers, Paper 2008-01-1292, April 2008. 
Appendix: Sample Laboratory Exercise

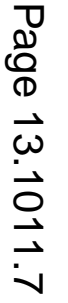




\section{Laboratory: Road Load Measurement Using Coastdown Techniques}

\section{Objective}

The SAE Recommended Practice provides uniform testing procedures for measuring the road load force on a vehicle as a function of vehicle velocity and for simulation of that road load force. This laboratory will employ a simplified-but less accurate-method which will be conducted by each group.

\section{Equipment Needed}

Thermometer, Diagnostic tool, vehicle, speedometer, barometer, tape measure, scales, floor jack

\section{References}

- SAE J1263 Recommended Practice

- SAE J1100 Recommended Practice

- Bosch Automotive Handbook

\section{Theory}

A vehicle encounters two forces in opposition to its motion as it is traveling on a level road. These forces are rolling resistance (RR), and wind resistance (WR). 


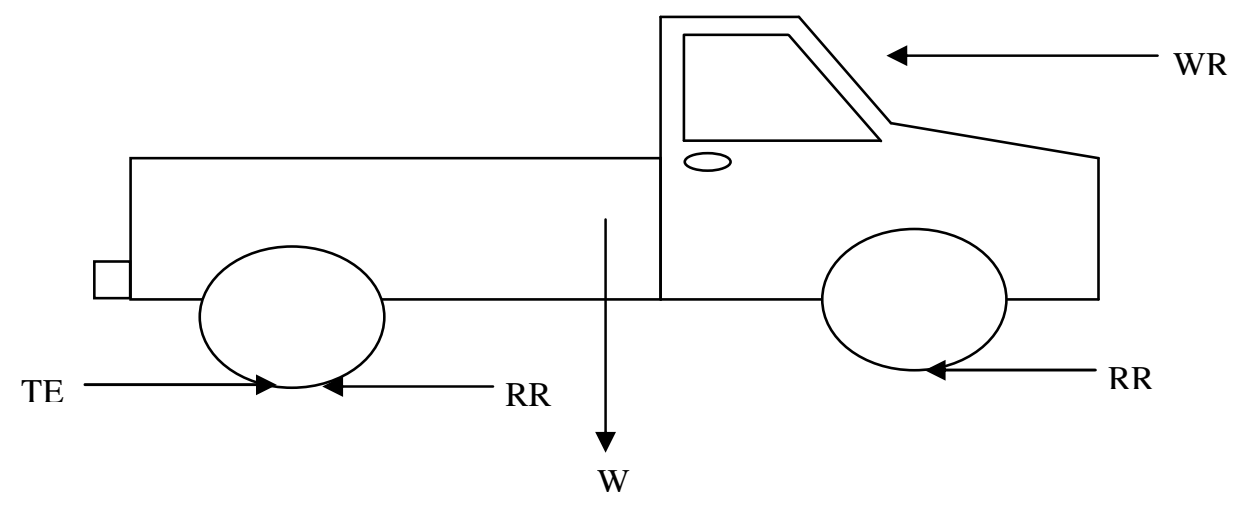

- Figure 1 Forces acting on a vehicle traveling on a level road.

The magnitude of force due to rolling resistance is a complex function of the tire-road interaction. In order to simplify the analysis, it is convenient to combine all of the terms into a non-dimensional parameter called the rolling resistance coefficient, $\mu$.

$$
R \cdot R .=\mu W\left(\mathrm{~N} \text { or } \mathrm{lb}_{\mathrm{f}}\right)
$$

In general, the rolling resistance coefficient is made up of both a constant term, $\mu_{0}$, and a term that varies with the square of the vehicle speed:

$$
\mu=\mu_{0}+\mu^{\prime} \cdot V^{2} \text {. }
$$

A simpler, but less accurate, approach can be taken by neglecting the variation in rolling resistance with the square of the vehicle speed. Assuming this value remains constant, the rolling resistance is seen to vary proportionally with the vehicle weight, $\mathrm{W}$, but it is not a function of vehicle speed:

$$
R \cdot R .=\mu_{0} W\left(\mathrm{~N} \text { or } \mathrm{lb}_{\mathrm{f}}\right)
$$

The magnitude of the wind resistance varies with the shape $\left(C_{D}\right)$ and size of the vehicle $\left(\mathrm{A}_{\mathrm{f}}\right)$, and is proportional to the square of the relative wind velocity. On a relatively calm day, the relative wind velocity reduces to the vehicle speed:

$$
W . R .=1 / 2 \rho C_{d} A V^{2} \text { (Newtons or lbf) }
$$

Where:

$$
\begin{aligned}
& \rho=\text { density of air, } \\
& C_{d}=\text { drag coefficient, } \\
& V=\text { relative wind velocity = vehicle velocity in still air, and }
\end{aligned}
$$


A = projected frontal area of the vehicle. This can be estimated frontal area using the following correlation:

Frontal Area $\left(\mathrm{m}^{2}\right)=0.8 *($ Body Height, meters $) *($ Body Width, meters $)$

Where:

Body Height and the width are found using the approach of SAE J1100.

Adding these two forces together results in a force called the road load force:

$$
R \cdot L .=R \cdot R+W \cdot R .
$$

Using the foregoing definitions and simplifications, the road load can then be written as:

$$
\text { (1.1) R.L. }=\mu_{0} W+1 / 2 \rho C{ }_{d} A V^{2} \text {. }
$$

It is readily apparent that the road load varies with the velocity of the vehicle squared. This equation has two unknowns, $\mu_{0}$ and $C_{D}$.

While the vehicle is in gear, the powertrain exerts a force on the vehicle called the tractive effort, T.E. Summing all of the forces results in the following relationship:

$$
\begin{gathered}
\sum F=m_{e} a \\
\text { T.E. }- \text { W.R. }- \text { R.R. }=m_{e} a, \text { or } \\
\text { T.E. }- \text { R.L. }=m_{e} a
\end{gathered}
$$

Since the vehicle is put into neutral during the coastdown, the tractive effort becomes zero. The Road Load Force can then be related to coast down rate as follows:

$$
\text { R.L. }=-m_{e} a=-m_{e} d V / d t \mathrm{~B}-m_{e} \frac{\left(V_{i+1}-V_{i}\right)}{\Delta t},
$$

where:

$m_{e}=$ effective vehicle mass. It is the sum of the final vehicle test mass and the effective mass of the rotating components. For, example the effective mass of the tire wheel and brake rotor is $\mathrm{I} / \mathrm{r}^{2}$, where $\mathrm{I}$ is the polar moment of inertia, and $r$ is the rolling radius. If no measurements of the wheel assemblies are available, the effective mass can also be approximated as shown in J1263 (eqt 10). 
Equation 1.2 provides a relationship between the road load force (which is a function of the vehicle speed as shown in eqt. 1.1) and deceleration. By measuring the rate of deceleration and the vehicle speed present during a coastdown, approximate values for the road load force can be determined at these various speeds.

In order to determine how the road load force is apportioned and to compare with other vehicles, it is customary to solve for the rolling resistance coefficient(s) and the coefficient of drag. These values provide insight into the causes of the road load force and let the designer compare values with other vehicles.

Equation 1.1 can then be substituted into equation 1.2, providing a relationship between the two unknown parameters $\mu_{0}$ and $C_{D}$, and the vehicle speed and rate of deceleration. By measuring the vehicle speed and deceleration (and by also determining the frontal area and air density), we can solve for the rolling resistance and the coefficient of drag. These coefficients can then be used to predict the motion of the vehicle in response to varying tractive effort and conditions.

The simplest method to determine the road load coefficients would require that two deceleration measurements be made to solve for the two unknowns, $\mu_{0}$ and $C_{D}$.

These two measurements would be used to determine values for the road load based upon the deceleration. These different road load values and velocities can then be used to find the two unknowns:

$$
\begin{aligned}
& R \cdot L_{\cdot_{A}}=K_{0} W+K_{2} V_{A}^{2}=K_{0} W+1 / 2 \rho C_{d} A V_{A}^{2}=-m_{e} \frac{\Delta V_{A}}{\Delta t_{A}} \text {, and } \\
& R \cdot L_{\cdot_{B}}=K_{0} W+K_{2} V_{B}^{2}=K_{0} W+1 / 2 \rho C_{d} A V_{B}^{2}=-m_{e} \frac{\Delta V_{B}}{\Delta t_{B}} .
\end{aligned}
$$

Where:

$V_{A}$ and $V_{B}$ are the average velocities experienced during each coastdown interval,

$\Delta \mathrm{V}_{\mathrm{A}}$ and $\Delta \mathrm{V}_{\mathrm{B}}$ are the changes in velocity during each coastdown interval, and

$\Delta \mathrm{t}_{\mathrm{A}}$ and $\Delta \mathrm{t}_{\mathrm{B}}$ are the changes in time during each coastdown interval.

Unfortunately, this simple approach involves the highest degree of error. The coefficient of rolling resistance, in particular, is sensitive to the actual vehicle speed; thus a better approach would be to ensure that the two deceleration measurements are made at widely varying initial speeds. This is exactly the approach used in the Bosch Automotive Handbook. 
A better approach still, is to use successive intervals to determine the two unknowns during a run. This will yield many values for these two unknowns, $\mu_{0}$ and $C_{D}$. These values can then be averaged together in order to improve accuracy.

The most involved method, which yields values of the highest accuracy, is to follow the SAE procedure. The SAE procedure requires multiple runs and an analysis of the data consistency, as shown the standard J1263.

\section{Kettering University Procedure}

In this laboratory, we will use a simplified SAE procedure. We will perform multiple runs in a manner similar to that used in the SAE standard. We will then average the coastdown data for road load calculations. Further, we will look at the effect that smoothing or curve fitting has on the data by performing a $2^{\text {nd }}$ order polynomial fit.

It is important to remember that the road load force and power can be calculated directly from the coastdown data without first estimating the coefficients. Further, the road load force and power found during the test is equal to the tractive effort that would have to be provided by the Powertrain during steady state operation at the given speed.

We will calculate the road load coefficients from the averaged or smoothed data. This will be done by applying equations 1.4 to successive time intervals in order to solve for the two unknowns, $\mu_{0}$ and $C_{D}$. This will yield many values for these two parameters which can then be averaged together.

The first part of the laboratory will use data that has been provided. The second part will allow you to test your own vehicle. 


\section{Part I - Calculations using given data}

Given data: See attached data sheet $(\mathrm{A})$

1. Using the raw data given, plot the Road Load Force vs. Velocity and the Road Load Power vs. Velocity, comment on the trends. Do not first calculate the parameters $C_{D}$ and $\mu_{0}$, determine this directly from the data as discussed in the text.

2. Calculate average values for $C_{D}$ and $\mu_{0}$ applying equations 1.4 to successive time intervals in order to solve for the two unknowns. After doing this for each pair of time intervals, simply average the values found.

3. Replicate the Road Load force vs. Velocity curve by using the values you determined for $C_{D}$ and $\mu_{0}$. Compare with that found directly from the data in step 1 and comment.

4. Using the road load coefficients calculated above, calculate how much additional power $(\mathrm{kW})$ this vehicle would require if you were to add 1000kg of cargo to the vehicle. (This question always comes up in the auto industry and everyone forgets how to calculate it.)

a. Assuming your vehicle is going $75 \mathrm{kph}$

b. Assuming your vehicle is going $125 \mathrm{kph}$

5. Calculate the speed where the power required to overcome aerodynamic drag first exceeds the power associated with the rolling resistance for this vehicle.

6. Using the road load coefficients previously calculated; plot Road Load Force vs. Velocity, Rolling Resistance Force vs. Velocity and the Wind Resistance Force vs. Velocity, comment on the trends (Do they make sense?). 


\section{Data Sheet A- Theoretical Data}

$$
\begin{aligned}
& M=1500 \mathrm{~kg} \\
& A=3 \mathrm{~m}^{\wedge} 2 \\
& \rho=1.2 \mathrm{~kg} / \mathrm{m}^{\wedge} 3
\end{aligned}
$$

\begin{tabular}{|l|l|}
\hline Velocity (kph) & Time (sec) \\
\hline 150 & 0 \\
\hline 145 & 1.24 \\
\hline 140 & 2.556 \\
\hline 135 & 3.955 \\
\hline 130 & 5.446 \\
\hline 125 & 7.036 \\
\hline 120 & 8.736 \\
\hline 115 & 10.556 \\
\hline 110 & 12.508 \\
\hline 105 & 14.606 \\
\hline 100 & 16.865 \\
\hline 95 & 19.302 \\
\hline 90 & 21.936 \\
\hline 85 & 24.886 \\
\hline 75 & \\
\hline & \\
\hline & \\
\hline 150 & \\
\hline 15252 \\
\hline 150
\end{tabular}

$$
\begin{aligned}
& \text { D } \\
& \stackrel{0}{0} \\
& \vec{D} \\
& \vec{\omega} \\
& \overrightarrow{0} \\
& \overrightarrow{\vec{D}} \\
& \overrightarrow{\vec{D}}
\end{aligned}
$$




\section{Part II -Experimental Data Procedure}

You will be performing a coastdown test on public roads, so use extreme care! NOTE: Use hazard lights during the test!!!!!!!

On some roads it might make sense to have a chase vehicle operating with its flashers on. This vehicle can drop back before the coastdown in order to warn following traffic.

Your goal is to accelerate to a vehicle speed above $100 \mathrm{kph}(62 \mathrm{mph})$ at the start of the test; however, only accelerate to a safe legal speed. Decide your own safe initial coastdown speed.

Do not coastdown to a stop-use the $\mathbf{J 1 2 6 3}$ final speed as a guide, but choose your own safe final coastdown speed.

Record your velocity-time data using the provided equipment.

1. Plot your Velocity vs. Time data for each run. Decide which data sets to use for your analysis. Remember to time shift your data (if necessary) so that all values start at zero time for your initial speed.

2. Using the averaged raw data, plot the Road Load Force vs. Velocity. This should come directly from the data, do not calculate the parameters $\mu_{0}$ and $\mathrm{C}_{\mathrm{D}}$ first!

3. Repeat the previous step using a 2 nd order polynomial fit of the data. Compare and comment.

4. Using the both the raw and fitted data, calculate the average road load coefficients using the Kettering method. That is, calculate average values for $\mathrm{C}_{\mathrm{D}}$ and $\mathrm{K}_{1}$ applying equations 1.4 to successive time intervals in order to solve for the two unknowns. After doing this for each pair of time intervals, simply average the values found. Compare and comment.

5. What is your best estimate for the parameters $\mu_{0}$ and $C_{D}$. Are these values reasonable? Why/Why not? 


\section{Pre_lab Questions:}

(To be determined before coming to the laboratory! Answers will be documented in your report.)

1. We are not going to weigh each wheel assembly for the test vehicle(s). How will we estimate the effective mass?

2. What does the as tested vehicle weight mean?

3. How will we make the measurements necessary in order to estimate the vehicle frontal area?

4. How many runs are required (at a minimum) to meet the SAE J1263?

5. Should all runs be made travelling in the same direction? Why/Why not?

6. What is the specified temperature range for testing?

7. What tire pressure is required?

8. How will you determine the air density?

9. Can this test be conducted on a grade?

\section{$\underline{\text { Additional Questions }}$}

1. According to SAE standard procedure, what is the warm-up procedure?

2. According to SAE standard procedure, is it proper to change lanes during experiment? 